\title{
Análisis estratégico de la banca ética en España a través de Triodos Bank. Financiación de proyectos sociales y medioambientales
}

\author{
Emilio Abad Segura \\ María del Carmen Valls Martínez
}

RESUMEN: La banca social es la respuesta a décadas de especulación financiera y a inversiones alejadas de un compromiso ético y cooperativo. En este sentido, es necesario reflexionar sobre la responsabilidad y el papel que juegan las entidades bancarias en el impacto y desarrollo social, en sus estrategias para captar el ahorro y en los criterios que aplican para definir la concesión del crédito y las inversiones. El sector bancario, tanto en España como en Europa, está modificando su rumbo. El costoso aprendizaje está culminando en la concentración con un número menor de entidades, aunque con más poder, y en la estabilidad de una banca social preocupada por la responsabilidad y transformación social del sistema económico. La banca ética constituye el instrumento necesario para gestionar el negocio bancario desde la transparencia con códigos sociales y medioambientales, sin olvidar la rentabilidad económica para resistir y permanecer en un sistema financiero exigente. El presente trabajo tiene como objetivos estudiar el origen y las características de la banca ética, analizar su implantación en España y examinar las condiciones e iniciativas que la entidad Triodos Bank realiza para posicionarse como banco líder con valores éticos.

PALABRAS CLAVE: Finanzas Éticas, Inversión Socialmente Responsable, Banca Social, Plan Estratégico, Triodos Bank.

CLAVES ECONLIT: A13, G21, M14, M21, M30.

Cómo citar este artículo / How to cite this article: ABAD, E. \& VALLS, M.C. (2018): "Análisis estratégico de la banca ética en España a través de Triodos Bank. Financiación de proyectos sociales y medioambientales", CIRIEC-España, Revista de Economía Pública, Social y Cooperativa, 92, 87-120.

Correspondencia: Emilio Abad Segura, Profesor Docente e Investigador; María del Carmen Valls Martínez, Profesora Titular de Universidad. Departamento de Economía y Empresa. Universidad de Almería. E-mail: eas297@ual.es, mcvalls@ual.es. 


\section{EXPANDED ABSTRACT}

\section{Strategic analysis of Ethical Banking in Spain through Triodos Bank. Financing social and environmental projects}

\section{Objectives}

Banking with ethical values appears as an alternative to traditional banking, answering the need of integrating ethics with entrepreneurial activity, prioritising the social commitment face to the economical profitability. In this sense, ethical banking limits the credit to non-socially responsible projects and it provides financing to vulnerable groups and investment with a positive environmental and social impact, at the same time that all its activities are transparent. The objective of this paper is to study the origin and features of the ethical banking, establishing the main differences with the traditional model, to analyse its implantation in Spain and to review the conditions and initiatives that Triodos Bank makes to position itself as the leader bank with ethical values.

\section{Methodology}

The implantation level and development of the ethical financial companies in Spain (Triodos Bank España, Fiare Banca Ética, Coop 57, Oikocredit España, etc.) has been analysed through the data of its financial statements. However, in order to study the Triodos Bank's corporate strategy, an external and internal analyse has been made. In this sense, the PESTEL analysis, which studies the Political, Economic, Sociocultural, Technological, Ecological and Legal factors that set up the environment and how they can affect the activity, is used to identify the factors of the general environment that influences the financial company's strategical position.

Regarding to the competitive environment, the Porter's "Five Forces" model has been analysed, its main competitors have been differentiated, as well as its main threats and opportunities. In order to do the internal analysis, four models have been used in the entrepreneurial scope: first, the weaknesses and strengths found in Triodos have been determined; second, the resources that contribute a competitive advantage according to the VRIO model, have been analysed; third, the "Value chain" described by Porter for the company, which describes the development of the activities performed by the bank to create value for the customer, is studied; and, finally, the Triodos Bank's organizational structure and the social and environmental data, are analysed. 


\section{Results}

The ethical banking's customers belong to groups with a high social commitment, who need to know the destiny of their savings. In the same way that it has happened in traditional financial companies, since the beginning of the crisis in the ethical institutions (Triodos Bank España, Fiare Banca Ética, Coop 57, Oikocredit España, etc.) the capital destined to the loan transactions was overcome by the bank customers' savings; the trend has been increasing and it is remarkable that in 2016 the savings almost doubled the capital given in loans. The increase experienced by the ethical banking is also reflected in the $48.26 \%$ increase in the number of customers and users from 2013 to 2016 , and in its amount of capital, which was almost 171 million euros in 2016, and all of this with a low rate of defaulting.

Regarding to Triodos, whose beginning in Spain is in 1998, even though it was in 2004 when it was converted into Triodos Bank España, the assets managed were 13,454 million euros in 2016, with a $9.40 \%$ annual increase. Regarding the sustainable sectors that are financed by Triodos, and knowing that the aim is to allocate to credit between $65 \%$ and $75 \%$ of own funds, it is remarkable environment $(38 \%)$, social $(24 \%)$, culture and leisure (14\%), and loans given to people, city councils and sustainable residential mortgages (24\%).

The Triodos Bank's strategic analysis shows that the distrust created by the non-ethical political practices has led to rules that search for the transparency of the financial system; moreover, the traditional banking's abusive practices have originated the demand of ethical products and companies by society. Likewise, the banking's development through the Internet and the mobile apps have implied the disappearance of regular offices. However, the threat of new financial companies in the sector of ethical finance is a reality, since the absence of a strict regulation for the ethical banking provokes that several traditional companies offer their saving and credit products under the name of sustainable, and this confuses customers. Nevertheless, Triodos is a European consolidated bank, it has a bigger infrastructure that its ethical competitors, it is a financially healthy company, with trained personal and it provides all kinds of financial products and services, what allows it to be competitive to face traditional banking.

The model VRIO notes that a resource provides a competitive advantage if it has the attributes: valuable $(\mathrm{V})$, rare or scarce $(\mathrm{R})$, inimitable $(\mathrm{I})$ and related to the organisation of the enterprise $(\mathrm{O})$. If it is applied to Triodos Bank, we can be sure that human resources (staff who is trained and with experience in the banking sector) and the intangible resources (solid image of a financial group with a successful trajectory) are a sustainable competitive advantage, while the tangible resources (branch network) and the client portfolio which share the company values, suppose a competitive parity with the rest of banking companies.

The Triodos' organizational structure, which is different from other financial companies and it is based in the Triodos' Foundation for the Administration of the Shares, allows it to have control of the decision making and not to be subjected to the shareholder's power, assuring the fulfilment of the ethi- 
cal values. On the other hand, the success of the implantation of Triodos depends to a great extent on the workers in the company, who have to be qualified and motivated with the mission and have to be able to put it in practice daily in the development of their work. The company has the commitment to invest an important amount of resources in training programs and professional development, with the purpose of training its workers. In this sense, the average expense in training by worker in 2016 was 1,731 euros.

\section{Practical conclusions and original value}

The inclusion of the ethical banking model in Spain is relatively recent; in fact, no companies like this have been created in the Spanish financial system as of yet. Up to now, the rule has been to stablish branch offices, following the model applied in other countries by consolidated companies, like Triodos Bank and Fiare Banca Ética, and to act according to the lines of financing that lead to the development of sustainable projects, sharing actively this banking business segment with financial companies which are called traditional banking, like BBVA, CaixaBank and Banco Santander. This sector may become saturated and, somehow, dilute efforts to ensure that the perception of society is based on a business model that includes social, environmental, cultural and economic results. The cooperatives that trade ethical saving and financing products, like Oikocredit and Coop57, also have an important role to establish and consolidate an ethical finance model, though more residual.

Ethical banking in order not to be a mere illusion associated with financial crisis periods and to become definitely in a consistent alternative, it should offer services and products similarly to the conventional banking and an economic and social profitability to contribute to their credibility and a clear differentiation in equality of conditions with the traditional banking.

This paper provides a strategic analysis without precedents about ethical banking in Spain, focused on Triodos, which is the leader ethical banking company. Traditional methodologies of external and internal analysis have been applied to this newly created sector providing useful information to its future implantation, as the strengths and weaknesses of this sector have been shown.

KEYWORDS: Ethical Finance, Socially Responsible Investment, Social Bank, Strategic Plan, Triodos Bank. 


\section{Introducción 1}

Desde el inicio de la última crisis financiera y bancaria mundial en 2007, se ha observado un aumento en la desconfianza del sistema financiero tradicional y un incremento en la fidelidad que el cliente deposita en las finanzas éticas (Karl, 2015; Alemán, 2015; Ruiz, Esteban y Gutiérrez, 2014; Soler y Melián, 2012; Pérez-Ruiz y Rodríguez, 2012; San José, Retolaza y Gutiérrez, 2011).

La banca con valores éticos, promovida por todos los sectores de la sociedad, surge de la necesidad de integrar la ética con la actividad empresarial, priorizando el compromiso social a la rentabilidad económica. Su transparencia operativa motiva que este modelo de banca realice actividades justificadas éticamente de captación y de inversión de fondos. De este modo, el criterio ético afecta íntegramente a la entidad y no sólo a la creación de determinados productos éticos o a la participación en criterios de responsabilidad social de la empresa (San José, Retolaza y Gutiérrez, 2011; Retolaza y San Emeterio, 2003).

El origen del enfoque social de los servicios financieros se remonta a la década convulsa de los setenta, que propició la aparición de diferentes movimientos e instituciones que solicitaban un sistema económico y financiero más comprometido y solidario con el medioambiente y las personas. Existía un convencimiento generalizado de que el sistema financiero podría ser una herramienta para obtener mejoras sociales (Sanchís, 2016; Alejos, 2014). Es indudable que el desarrollo necesita ser sostenible, y para ello se debe poner un especial énfasis en favorecer y promocionar una cultura de desarrollo social y respeto con el medioambiente, para así obtener rendimientos económicos y de mejora social (Mishra, 2015; Dorasamy, 2013; De la Cruz, Sasia y Garibi, 2006).

Así, la banca ética, compuesta por bancos y sociedades cooperativas de crédito, ejerce sus funciones de intermediario financiero dentro de la estructura y regulación del sistema financiero, cuya actividad principal es la de captar fondos de sus clientes para conceder créditos y realizar proyectos de inversión con carácter ético, dando de este modo sentido a las inversiones de los ahorradores sensibilizados con el destino de su capital (Sanchís y Pascual, 2017; Castro y Romero, 2011; Cabaleiro y Rodríguez, 2008). Por esta razón, los riesgos financieros adoptados por el sector financiero han repercutido sobre el resto de sectores, de modo que esta conducta continuada ha contribuido a que la banca $y$, en general, el sector del crédito tomen de alguna forma conciencia del perjuicio al que exponen a la sociedad y hayan posibilitado la tendencia creciente en los productos de activo y pasivo éticos dirigi-

1.- Este trabajo ha sido parcialmente financiado por el proyecto "La sostenibilidad del sistema nacional de salud: reformas, estrategias y propuestas" (DER2016-76053-R), Programa Estatal de I+D+l Orientada a los Retos de la Sociedad. Ministerio de Economía y Competitividad (España). 
dos a la confianza de los clientes comprometidos y el desarrollo de esta banca social (Serrano, 2017; Paulet, Parnaudeau y Relano, 2015; Condosta, 2012; Toña, Sasia y Garibi, 2006).

El trasfondo y la naturaleza de este modelo adquieren sentido cuando se cuestiona el derecho al crédito en las sociedades capitalistas. Asimismo, la banca sostenible ha emergido como una respuesta alternativa en la situación económica actual al poner en duda la intermediación financiera tradicional e intenta ofrecer un planteamiento más ético (De la Cruz y Sasia, 2010; Knights, 2009).

En consecuencia, su actividad se dirige a restringir el crédito a determinadas iniciativas que no cumplan los criterios responsables que establecen, con objeto de actuar como freno a proyectos empresariales que tienen un efecto negativo para la sociedad. En efecto, se puede considerar como una evolución de la intermediación financiera, reconociendo ahora un valor social en el mecanismo de su función y plantear quién y por qué tiene derecho al crédito (Ochoa, 2013; Sasia, 2012).

La deteriorada imagen de las entidades tras la crisis financiera obliga a las compañías a elaborar estrategias de Responsabilidad Social Corporativa (RSC), contemplando que su actividad debe ir ligada a las necesidades de los diversos grupos de interés. En este contexto, se ha evaluado la percepción que los clientes tienen de las entidades bancarias y la transición que supone generar de nuevo confianza en el sector financiero (Ochoa, 2013; Rosero, Pinzón y Ramírez, 2013; Pérez-Ruiz y Rodríguez, 2012).

Aunque la actividad bancaria que lleva a cabo tanto la banca convencional como la banca ética es similar, puesto que ofertan productos financieros afines, ésta responde a criterios sociales y culturales muy diferentes (Palomo-Zurdo, Gutiérrez-Fernández y Fernández-Torres, 2017). Como es sabido, el objetivo principal de la banca tradicional es el económico, es decir, trata de maximizar la rentabilidad y los beneficios con su actividad, independientemente, en general, del impacto que pudieran tener los proyectos que financia (Castro y Romero, 2011; San José y Retolaza, 2007; Toke, 2005). En otro orden, para que una entidad pueda ser considerada como ética debe financiar actividades económicas que tengan un impacto social positivo, además de ser viables y obtener beneficios. En este sentido, además de ejercer y operar como una entidad convencional, se comporta como un servicio público comprometido con aportar servicios básicos a la sociedad, buscando así evitar la exclusión de los colectivos más vulnerables, de modo que su gestión incluye tanto la responsabilidad interna, referida a la transparencia de su operatividad, como la externa, en cuanto es un agente del sistema financiero que debe canalizar o redistribuir el ahorro hacia la inversión (Baraibar-Díez, Odriozola y Fernández, 2017; Cornée, 2017; Narrillos, 2010). Es relevante también el hecho de que la banca con valores tiene la condición de herramienta política (Gassiot, 2013; De la Cruz y Sasia, 2010), estableciendo la unión entre el reivindicado derecho al crédito y la intermediación financiera desde el ámbito de la solidaridad y en contraste con la especulación (Halamka y Teplý, 2017).

La banca social no emerge como la solución al problema del crédito ni como el único promotor de los proyectos de inversión que contemplen los beneficios sociales y medioambientales como obliga- 
torios, sino que con su actividad pretende delimitar el compromiso y la ética en un sistema financiero que vuelva a suscitar interés en la sociedad y en los clientes decepcionados (Caldarelli et al., 2016; Cornée, Kalmi y Szafarz, 2016; Mozib, 2015).

Sin embargo, aunque la investigación en la banca ética es ínfima, es necesario destacar que está incrementándose en los últimos años y existe un reconocimiento por parte de la comunidad científica que muestra un interés en definir temas intrínsecos a este modelo bancario como son, entre otros, establecer las características que permiten a una entidad pertenecer a este modelo de finanzas, 0 determinar la creación de valor que aportan con su actividad (Bosheim, 2012). Este déficit de investigación puede estar sustentado en la falta de regulación que delimite a este modelo de banca y, como se ha comentado, al no estar definidas estrictamente sus características y particularidades ni existir un registro, una entidad puede decidir si se vincula a este movimiento.

Por otro lado, llegado a este punto se hace necesario reflexionar acerca de si en España, como ha ocurrido en otros países de Europa, este modelo de banca tiene opciones de, en primer lugar, reconocerse y, posteriormente, consolidarse como un referente en el negocio bancario (Pulejo, Marisca y Rappazzo, 2015).

En este contexto, hay que destacar entre las entidades que operan con el modelo bancario ético en España el asentamiento de Triodos Bank, incluso a nivel europeo, al incrementar sus cifras de negocio y beneficios desde su implantación (Chew, Tan y Hamid, 2016; Manini y Amat, 2017; Alejos, 2014; Retolaza y San Emeterio, 2003; Cowton y Thompson, 2001).

Para evaluar si la consolidación de la banca social es un hecho, se hace necesario el desarrollo de trabajos e investigaciones que estudien, por un lado, la cuota de mercado que presentan el conjunto de entidades financieras sostenibles en el sector del crédito y la inversión y, por otro, si la percepción e imagen que tienen los clientes, usuarios y la sociedad están en línea con la misión que define este modelo bancario (Relano, 2015). Los resultados que se obtengan explicarán, a efectos prácticos, la importancia de su implantación a una escala nacional e internacional y no que sólo sea una respuesta a las necesidades de crédito de pequeñas zonas vinculadas al subdesarrollo.

El objetivo principal del presente trabajo es identificar las características intrínsecas a la banca ética, estableciendo las diferencias más relevantes con el modelo tradicional. En esta línea, analizaremos la estrategia corporativa de Triodos Bank, referente de la banca ética en Europa y España, con objeto de conocer cómo está creciendo y cómo el valor añadido genera una ventaja competitiva.

La estructura del trabajo es la siguiente: en la Sección 2 se estudian las condiciones que han posibilitado que la ética se haya podido establecer en las entidades bancarias en España; en las Sección 3 se analizan el origen e implantación de Triodos Bank; en la Sección 4 se realiza un análisis estratégico de Triodos Bank España, la entidad que de forma más exitosa está desarrollando su actividad bancaria con valores sostenibles; y, por último, en la Sección 5 se presentan las conclusiones obtenidas. 


\section{La banca ética en España: origen y evolución}

La inserción de las finanzas socialmente responsables en la economía española se asocia a la creciente preocupación por los temas sociales en las últimas décadas por un amplio sector de la sociedad. De este modo, en la década de los ochenta comienzan a darse los primeros pasos en la financiación ética y solidaria en el sector bancario, diferenciándose entre el modelo cooperativo, donde priman las personas ante el capital, y el modelo del sistema bancario, que realiza inversiones y ofrece una serie de productos financieros bajo el criterio ético. Junto a estos modelos se ha desarrollado la banca solidaria cuya función principal es la de aportar soluciones financieras a los colectivos excluidos, por medio de distintos programas sociales que financian el trabajo y sus necesidades primarias (De la Orden y Sánchez, 2016; Vidal et al., 2006).

Es preciso aclarar que, la banca social engloba a todas aquellas entidades del negocio bancario cuya gestión está guiada por los principios de transparencia, comunicación y participación y que tienen un impacto social luchando contra la pobreza y la exclusión o favoreciendo el desarrollo sostenido mediante la preservación del medio ambiente, todo ello respetando valores éticos (Soler y Melián, 2012). Así pues, podemos distinguir dentro de la banca social dos grandes categorías: por una parte, aquellos bancos dedicados a la reducción de la pobreza en el tercer mundo y, por otro lado, los denominados bancos éticos, que operan en los países desarrollados. En este sentido, considerando nuestro entorno, es usual hablar indistintamente de banca social y banca ética, si bien es cierto que el concepto de banca social es más amplio.

Las cooperativas de crédito pueden considerarse un antecedente de la actual banca ética, puesto que en sus orígenes fueron creadas para evitar la exclusión financiera de pequeños y medianos agricultores y artesanos, que no conseguían financiación de la tradicional banca comercial y de negocios; su estructura de gobierno es democrática y su objetivo no es maximizar el beneficio para retribuir al capital, sino proporcionar servicio a sus socios. Análogamente podemos considerar la obra social de las cajas de ahorro.

Ahora bien, lo que distingue realmente a los bancos éticos, además de su gestión y transparencia, es el tipo de productos que comercializan. Los productos y servicios éticos en sentido estricto son aquellos que se suministran a empresas y organizaciones con criterios sociales y medioambientales, decidiendo a través de criterios positivos (qué empresas realizan este tipo de actividades y, por tanto, deben financiarse) 0 criterios negativos (qué empresas van en contra de este tipo de actividades y, en consecuencia, no deben ser atendidas por el banco). Asimismo, proporcionan productos y servicios de financiación solidaria, destinados a financiar proyectos beneficiosos para la comunidad. Por último, encontramos los productos y servicios solidarios, que son aquellos que destinan una parte 
de los beneficios obtenidos con ellos a organizaciones o proyectos solidarios, como ONG (Iturrioz, Mateu y Valor, 2005).

Algunos de los productos que comercializa la banca tradicional española se encuadran dentro de estos grupos. Fundamentalmente, todas las entidades suelen comercializar planes de pensiones y fondos de inversión éticos. Si bien las cajas de ahorro y cooperativas de crédito están en mejor posición para ello, en España los bancos son líderes en inversión socialmente responsable, debido a su mayor volumen de operaciones y a su mayor capacidad de innovación (Valor et al., 2007). Ahora bien, la comercialización de determinados productos concretos se lleva a cabo más como estrategia de marketing, pues no es un espíritu que se extienda al conjunto de la oferta de las entidades. Esto es, no son banca ética propiamente dicha, si bien esa parte de su oferta quedaría dentro del campo de las finanzas éticas.

El sector bancario en España lleva décadas experimentando un cambio de rumbo, en la búsqueda de una alternativa que aglutine criterios económicos y sociales. Por un lado, se ha producido una concentración de las entidades financieras convencionales y, por otro lado, se ha originado un crecimiento en el sector de la banca alternativa o social, tanto de las cooperativas de crédito como de los bancos éticos. Sin embargo, destaca el escaso marco normativo aplicable al sector de la banca ética en España, en oposición a lo que ocurre en los países del entorno (San José, Retolaza y Pruñonosae, 2014). En este sentido, el débil posicionamiento del concepto de banca ética llevó a la Comisión Nacional del Mercado de Valores (CNMV) a aprobar y, posteriormente, a elaborar a la Asociación de Instituciones de Inversión Colectiva y Fondos de Pensiones (INVERCO) la Circular, 8 de abril de 2014, sobre la aplicación de criterios medioambientales, sociales y de gobierno corporativo (ASG) en la política de inversión de las Instituciones de Inversión Colectiva (IIC), con objeto de proteger al inversor de una publicidad engañosa en los productos financieros con el calificativo "ético". Por otro lado, también habría que señalar la norma AENOR: UNE 165001:2012, que presenta los requisitos que deben cumplir los productos financieros de inversión para ser calificados como socialmente responsables.

En esencia, dentro de las finanzas éticas en España se distinguen instrumentos financieros tales como productos financieros éticos asociados a los mercados de valores, que incluyen los fondos de inversión éticos, los fondos de pensiones éticos y las acciones y bonos éticos, microcréditos, instrumentos crediticios y de ahorro ético, y la propia banca ética (Gutiérrez, 2004).

Los clientes de esta banca alternativa pertenecen a colectivos con un alto compromiso social que necesitan conocer el destino de sus ahorros. Entre éstos podemos encontrar a las entidades sociales que forman parte de los movimientos de Economía Alternativa y Solidaria (REAS), las organizaciones no gubernamentales para el desarrollo, las congregaciones religiosas y a los ciudadanos socialmente responsables (Alfonso, 2017; Toña, Sasia y Garibi, 2006). Así, la banca social está demostrando que es una alternativa fiable y resistente a las tentaciones del sistema financiero que tanto ha deteriorado la imagen del sector bancario. 
Del mismo modo que ha sucedido en entidades financieras tradicionales, desde el inicio de la crisis en las instituciones éticas (Triodos Bank España, Fiare Banca Ética, Coop 57, Oikocredit España, etc.) el capital destinado a operaciones de préstamo fue superado en 2011 por el ahorro de los clientes bancarios (véase Gráfico 1); la tendencia ha sido creciente en estos ocho años y destaca que en 2016 el ahorro prácticamente duplica al capital concedido en préstamos.

\section{Gráfico 1. Evolución del ahorro y préstamo en el sector de las Finanzas Éticas en España (en millones de euros) (2008-2016)}

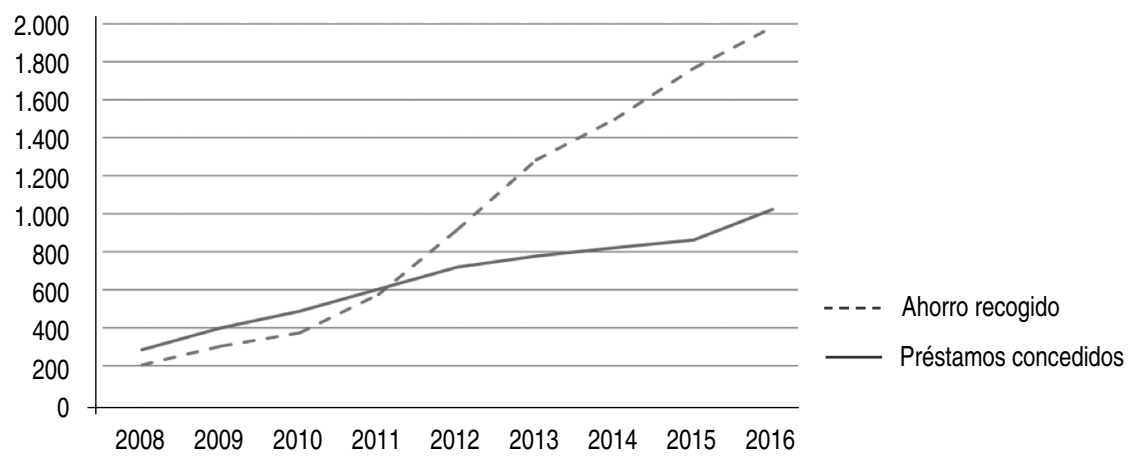

FUENTE: Elaboración propia a partir de los datos del 2008 al 2016 del Barómetro de las Finanzas Éticas.

El comportamiento responsable y la credibilidad que están acumulando las entidades éticas, ayudan a cambiar la mentalidad de una sociedad que pretende planificar los riesgos y ser partícipes de las reglas de un sistema que ha actuado contra la calidad de vida y la dignidad humana. En este sentido, el crecimiento experimentado por la banca ética también se refleja en el incremento del $48,26 \%$ del número de clientes y usuarios desde 2013 a 2016, así como en su volumen de capital, que asciende a casi 171 millones de euros en 2016, y ello con una baja tasa de morosidad, pues el cociente entre el valor de los créditos dudosos y el valor de la cartera de créditos totales se sitúa en el 6,12\% (véase Tabla 1). 


\section{Tabla 1. Banca Ética en España: Evolución $N^{\circ}$ de Clientes/ Usuarios, Tasa de morosidad y Capital (2013-2016)}

\begin{tabular}{|cccc|}
\hline Año & Clientes/Usuarios & Tasa Morosidad (\%) & Capital (€) \\
\hline 2013 & 159.408 & 4,18 & n.d. \\
2014 & 187.383 & 8,17 & 129.687 .542 \\
2015 & 214.922 & 7,04 & 144.814 .168 \\
2016 & 236.341 & 6,12 & 170.790 .061 \\
\hline
\end{tabular}

FUENTE: Elaboración propia a partir de los datos del 2013 al 2016 del Barómetro de las Finanzas Éticas

Como ha quedado expuesto anteriormente, las finanzas éticas se extienden más allá del sector bancario. En concreto, en España encontramos las siguientes entidades de finanzas éticas: en primer lugar, cualquier entidad financiera que comercialice algunos productos éticos (en la parte que corresponda a estos productos), siendo los más extendidos los fondos de inversión y planes de pensiones. En segundo lugar, entidades éticas pertenecientes al sector bancario, como Triodos Bank (objeto de estudio en este artículo) y FIARE Banca Ética, único proyecto originario de nuestro país; la Fundación FIARE fue creada en 2003 y en 2005 firmó un contrato de agente con Banca Popolare Etica Scpa, operando como una sucursal de ésta en España. Por último, en tercer lugar, encontramos multitud de experiencias no bancarias y, por tanto, no sometidas al control del Banco de España.

Dentro de este último grupo hay que destacar las sociedades cooperativas de servicios financieros, que apuestan por un enfoque bancario alternativo y que sería recomendable que evolucionasen hacia formas más solventes, como las cooperativas de crédito (Cabaleiro y Rodríguez, 2008); ciertamente en países como México y Brasil que han apostado fuertemente por ellas, se ha permitido el acceso a los servicios bancarios de más de setenta millones de personas (Buendía, Redjah y Tremblay, 2012). La más significativa en España es Coop57, que capta el ahorro de la sociedad civil para canalizarlo hacia la financiación de entidades de la economía social y solidaria que sean socios de Coop57 y que aporten algún tipo de valor añadido para su entorno y para el conjunto de la sociedad. Otra experiencia no bancaria destacable es Oikocredit, una cooperativa internacional de finanzas éticas que canaliza los ahorros de personas y organizaciones comprometidas de países desarrollados hacia la financiación de proyectos empresariales con contenido social en países en vías de desarrollo; en España solo financia proyectos o empresas de comercio justo, o muy excepcionalmente proyectos productivos que tengan un impacto social positivo muy directo en países del sur.

Finalmente, podemos destacar otras experiencias no bancarias de finanzas éticas en España, como Acció solidàri contra l'atur, Ideas comercio justo, Banca ética Badajoz, GAP, Estalvi Solidari, Elkarcredit, ABA Mérida, ACAF, AIS O'Peto y Fondo solidario "Paz y Esperanza". Los datos correspondientes a todas ellas, junto con los referidos a Triodos España, FIARE España, Coop57 y Oikocredit son los que aparecen recogidos en el Gráfico 1 y en la Tabla 1. 
El movimiento de la banca social busca asociarse para generar vínculos entre las entidades y formar una alianza más visible en el sector de las finanzas mundiales. Así, surgen instituciones y redes en este sentido como: The Institue for Social Banking (ISB), la Federación Europea de Bancos Éticos y Alternativos (FEBEA), la International Association of Investors in the Social Economy (INAISE) y la Global Alliance for Banking on values (GABV). Cabe señalar que la GABV es una red internacional que tiene por finalidad ampliar el impacto de la banca ética y sostenible a nivel global y que en junio de 2017 estaba formada por 7 socios estratégicos y 43 bancos sostenibles independientes, entre los que se encuentran diez europeos: Alternative Bank Switzerland y Freie Gemeinschaftsbank Genossenschaft (Suiza), Banca Popolare Ética (Italia), Crédit Coopératif (Francia), Culture Bank (Noruega), Ekobanken (Suecia), GLS Bank (Alemania), Magnet Bank (Hungría), Merkur Resource Bank (Dinamarca) y Triodos Bank (Países Bajos) (GABV, 2017). Destaca esta última entidad como uno de los miembros fundadores de la GABV y que, en la actualidad, es un referente en la banca que promueve la renovación social desde el sistema financiero.

\section{Estudio del caso de Triodos Bank en España}

\subsection{Origen e implantación de Triodos Bank}

El periplo de Triodos Bank comenzó a gestarse en 1968 cuando un grupo de profesionales del Derecho y la Economía decidieron gestionar de forma sostenible su capital. Así, en 1971 se crea la Fundación Triodos, dedicada a captar fondos de donantes privados con objeto de invertirlos en actividades con fines sociales, medioambientales y culturales. Posteriormente, en 1980, la fundación da paso a la entidad financiera de carácter social y medioambiental Triodos Bank N.V. en Zeist, Países Bajos, dando lugar al referente en Europa en banca ética y sostenible. Posteriormente, el desarrollo de su actividad bancaria les ha permitido crear una serie de fondos verdes y de microcréditos, además de una rápida expansión, constituyéndose como una entidad respetada en el sector ético y financiero, ajena a la especulación.

Así, el Grupo Triodos engloba las actividades bancarias de Triodos Bank y la actividad de inversión de Triodos Investment Management y de Banca Privada, con presencia en los Países Bajos, Bélgica, Reino Unido, España, Alemania, y cuenta con una agencia en Francia.

En particular, como señala en su web corporativa, Triodos Bank es una sociedad anónima que se rige por las leyes holandesas y su actividad es la de financiar empresas, instituciones y proyectos con valor social, medioambiental y cultural, a partir de los ahorros e inversiones que apuestan por conseguir una sociedad sostenible. 
En la actualidad, los ahorros captados de sus clientes les permiten financiar proyectos sostenibles, ofreciendo un modelo bancario basado en la transparencia. Además de su presencia en varios países europeos, desarrolla una intensa actividad en diversos países de América Latina, Asia y África, con la aplicación de sus fondos de inversión y microcréditos.

La reputación del banco se ha ensalzado, especialmente, a partir de la vulnerabilidad de las compañías del sector financiero que se centraron en la consecución de la rentabilidad económica (Serrano, 2017). Sin embargo, las demandas sociales exigen que, además de los resultados, la percepción y la información que aporten sea transparente, de modo que la imagen corporativa repercutirá en la confianza de los clientes, puesto que los problemas de solvencia, las fusiones de la banca tradicional, e incluso la globalización e innovación financiera, pueden generar incertidumbre en la consolidación de la banca social. Por otro lado, los usuarios cada vez más exigen que la RSC en las entidades financieras no sea sólo un concepto académico, sino que se convierta en una herramienta que se relacione directamente con las iniciativas e inversiones sociales, culturales y medioambientales (Pérez-Ruiz y Rodríguez, 2012; Serrano, 2017).

Una de las cualidades en las que destaca Triodos es la de establecer nexos de unión y asociación con instituciones que posibiliten su desarrollo y crecimiento. En este sentido, para mejorar la información que presenta a los grupos de interés, detalla sus notificaciones mediante el contacto directo con éstos y considera sus puntos de vista, mantiene un feedback con especialistas en la industria bancaria sostenible de la Global Alliance for banking values (GABV, 2016), y además realiza consultas periódicas a la United Nations Environment Programme - Finance Initiative (UNEP FI), a la Dutch Transparency Benchmark del gobierno holandés, al International Integrated Reporting Council (IIRC), al Global Reporting Initiative (GRI) y a la guía sobre inversiones responsables Fair Finance Guide International (FFGI).

En 2016, el patrimonio gestionado por el Grupo Triodos Bank era de 13.454 millones de euros, con un incremento del 9,40\% interanual, considerando que el crecimiento esperado debía estar situado entre el $5 \%$ y el $15 \%$. En cuanto a los sectores sostenibles que financia, por la acumulación de experiencia y conocimientos adquiridos y conociendo que el objetivo es destinar al crédito entre el $65 \%$ y el $75 \%$ de los fondos propios, destacan medioambiente (38\%), social (24\%), cultura y ocio (14\%), y préstamos concedidos a particulares, ayuntamientos e hipotecas sostenibles residenciales (24\%). Así, la calidad de la cartera de crédito, en términos generales, es satisfactoria conforme a la caída de la calidad crediticia experimentada en numerosos bancos europeos, y teniendo en cuenta tanto el contexto económico global de crecimiento limitado como la difícil coyuntura económica existente. 


\subsection{La presencia de Triodos Bank en España}

Su origen en España data de 1998 con la creación de la sociedad mercantil Proyecto Trust, que tenía por finalidad actuar como consultora e invertir en proyectos de los sectores social, cultural y medioambiental. Posteriormente, se convierte en Triodos Investments, agente financiero de Triodos Bank en España; y, finalmente, en septiembre de 2004 se convierte en Triodos Bank España, con capacidad plena para operar como entidad financiera con el número de registro 1.491 en el Banco de España. Actualmente, en 2017, dispone de oficinas en prácticamente todas las comunidades autónomas, excepto en Cantabria y La Rioja, y en las ciudades autónomas de Melilla y Ceuta.

La entidad ejerce la actividad de intermediación entre el ahorro y el crédito en el sector bancario, es decir, además de realizar otros servicios financieros, se centra en la captación de recursos ajenos y en la concesión de préstamos y créditos a sus clientes. Dentro de este sector, realiza su actividad en las finanzas éticas.

Con su política bancaria contribuye a una sociedad que fomente la calidad de vida, facilita un uso responsable del dinero para fomentar un desarrollo sostenible y oferta productos financieros éticos. En esta línea, Triodos Bank para financiar una actividad principalmente valorará el beneficio que aporta a la sociedad y al medioambiente. Así, en la búsqueda de este criterio ético identificará sectores sostenibles en los que apoyar el desarrollo y la consolidación de empresas y proyectos innovadores, seleccionará iniciativas de la economía real que aporten un valor añadido de tipo social, medioambiental y cultural, y, por último, supervisará el uso que se realiza de los préstamos concedidos.

Destaca que es un banco que no cotiza en Bolsa con el objeto de, como el grupo mismo señala, no estar sometidos a los vaivenes de precios que se producen en el mercado de capitales. De este modo, gestionan profesionalmente un banco sostenible y viable, apoyando así el desarrollo de la banca con valores. Por ello, las acciones de la entidad están gestionadas por la Fundación para la Administración de las Acciones de Triodos Bank (SAAT).

De acuerdo con el barómetro de Finanzas Éticas y Solidarias de 2016, Triodos Bank España es la entidad con las características más similares a la banca convencional, excepto con el valor añadido que supone invertir en iniciativas o proyectos culturales, sociales y medioambientales que tengan un impacto positivo en la sociedad. 


\section{Análisis de la estrategia corporativa de Triodos Bank}

Triodos Bank viene poniendo en práctica un modelo de negocio bancario al servicio, a diferencia del modelo tradicional, de una serie de valores que incluyan a la sociedad, el medioambiente y la cultura. Esto significa que, como negocio sustentable, es una entidad constituida para establecer el equilibrio en la contabilidad del "triple resultado", es decir, el resultado neto del ejercicio económico incluye el esfuerzo y el desempeño puesto por el banco en las dimensiones social, económica y ambiental.

La fuerte competencia en este negocio y el protagonismo adquirido por la clientela derivado del acceso instantáneo y económico a la información, hacen obligatorio desarrollar un plan estratégico que responda a las modificaciones en el entorno para la toma de decisiones en un complejo y global negocio bancario, con el objeto de reaccionar ante los cambios regulatorios, el mercado financiero y conocer los recursos propios que garanticen la supervivencia y la rentabilidad económica y social de la entidad.

\subsection{Análisis externo}

Con objeto de analizar la situación actual y futura de Triodos Bank, se describe el entorno en el que desarrolla la actividad bancaria, detectando las oportunidades y amenazas que surgen, y se analiza la estrategia con la que se posiciona de manera sólida en el mercado financiero español.

\subsubsection{Análisis de los factores de influencia del entorno}

Para identificar los factores del entorno general que influyen en la posición estratégica de la entidad financiera se utiliza el análisis PESTEL, que analiza los factores Políticos, Económicos, Socioculturales, Tecnológicos, Ecológicos y Legales que configuran el entorno y cómo pueden afectar a su actividad (Tabla 2).

La descripción del entorno ha puesto de manifiesto que las actividades poco éticas llevadas a cabo por el sector financiero provocaron la crisis y el incremento de la desigualdad social, con el consiguiente deterioro en la percepción de las entidades financieras por la sociedad.

En cuanto al entorno en el que ejerce Triodos su actividad, hay que recalcar que la crisis ha supuesto la necesidad de aportar eticidad a la esfera financiera, de modo que en este escenario se ha perseguido la incorporación de valores y hábitos que subsanen los errores sucedidos con el objetivo de volver a generar la confianza perdida por la sociedad en el sector financiero. 
Tras este período, el resultado ha sido una obligada reestructuración y recapitalización del sistema bancario español, adoptándose una serie de medidas que reforzaran la resistencia del sector a los conflictos financieros internacionales. Estas medidas, fundamentalmente, se han basado en un aumento de las provisiones de las entidades financieras y en la transparencia, con la finalidad de corregir la confianza de los clientes y posicionar el sector en una situación de estabilidad, con la coordinación del Banco de España y las autoridades financieras europeas (Banco de España, 2017).

El período convulso experimentado por la crisis financiera ha conducido a una exigente reestructuración de la banca tradicional, y ha estado acompañada por un distanciamiento entre la clase política y el resto de la sociedad, derivada fundamentalmente por los recortes al estado del bienestar y por una elevada tasa de desempleo, que ha motivado una larga situación inestable desde el punto de vista social. Por estas razones, las instituciones financieras están esforzándose en mejorar la percepción por parte de los ciudadanos, con medidas relacionadas con la transparencia de su actividad, con la regulación del funcionamiento de sus órganos de gobierno con medidas más estrictas y evitando la asimetría de información.

Por otro lado, las instituciones europeas han marcado la ruta económica en España poniendo en práctica una serie de medidas económicas que trataran de solventar la precaria situación, de modo que la restricción del crédito ha provocado problemas de liquidez en el tejido empresarial con el resultado del cierre de numerosas empresas.

En cuanto al desarrollo tecnológico, éste ha posibilitado que la actividad bancaria esté usando nuevos canales de distribución virtuales en detrimento de las sucursales físicas, para realizar operaciones financieras y vender sus productos.

\section{Tabla 2. Análisis PESTEL}

\begin{tabular}{|l|l|}
\hline Entorno & Factores influyentes y consecuencias \\
\hline Político & $\begin{array}{l}\text { La desconfianza generada por las prácticas políticas poco éticas ha dado lugar a normas que buscan la } \\
\text { transparencia del sistema financiero. }\end{array}$ \\
\hline Económico & $\begin{array}{l}\text { La crisis económica ha dado lugar a una reestructuración del sistema bancario con procesos de fusiones y } \\
\text { absorciones, disminución del número de entidades, así como unos bajos tipos de interés. }\end{array}$ \\
\hline Social & $\begin{array}{l}\text { Las prácticas abusivas de la banca tradicional, como las cláusulas suelo, preferentes, desahucios, etc., } \\
\text { ha supuesto la demanda de productos y entidades éticas por la sociedad. }\end{array}$ \\
\hline Tecnológico & $\begin{array}{l}\text { El desarrollo de la banca a través de Internet y las aplicaciones móviles ha implicado la desaparición de oficinas } \\
\text { físicas, la adaptación a las necesidades del cliente, mayor competencia y menores márgenes. }\end{array}$ \\
\hline Ecológico & $\begin{array}{l}\text { La preocupación creciente por el medio ambiente ha supuesto el uso responsable de recursos (como la } \\
\text { supresión del papel) y la utilización de materiales respetuosos con el medioambiente (oficinas sostenibles). }\end{array}$ \\
\hline Legal & $\begin{array}{l}\text { Existe una legislación específica para entidades financieras, en general, y para entidades bancarias, en } \\
\text { particular. }\end{array}$ \\
\hline
\end{tabular}

FUENTE: Elaboración propia. 


\subsubsection{Análisis del entorno competitivo}

El análisis de las cinco fuerzas de Porter y de las principales entidades competidoras de Triodos Bank en España, identifica el entorno competitivo de las entidades de crédito españolas y permite detectar las oportunidades y amenazas que encuentra el banco en el negocio financiero.

\subsubsection{Las cinco fuerzas de Porter}

El modelo estratégico de las cinco fuerzas de Porter permite desarrollar una serie de ventajas competitivas, a través del análisis de los proveedores, clientes, competidores existentes, productos o servicios sustitutivos y nuevos competidores. De este modo, se realiza un diagnóstico asignando un valor a cada fuerza para así determinar el poder de negociación de los clientes y de los proveedores, identificar la amenaza de los nuevos competidores y de los productos o servicios sustitutivos y determinar la rivalidad entre los competidores existentes (véase Tabla 3).

Este análisis nos lleva a interpretar que la amenaza de nuevas entidades financieras en el sector de las finanzas éticas es una realidad, puesto que, al no existir aún una regulación estricta para la banca ética, diversas entidades tradicionales ofrecen sus productos de ahorro y crédito bajo el calificativo de sostenible, llevando a la confusión al cliente.

Asimismo, si la competencia proviene de entidades que actúan en el mismo mercado y realizan la misma función, es decir, aquella que satisface las mismas necesidades respecto al mismo cliente, en España la rivalidad entre las propias entidades de banca ética es débil, puesto que el tamaño de éstas es aún pequeño y se encuentran en fase de implantación.

Actualmente, la competencia directa son las cooperativas u organizaciones cuyo fin es promover el bien social, además de las fundaciones y proyectos de la banca tradicional, que en el camino de mejorar su imagen aplican criterios de sostenibilidad en inversiones en sectores sociales, medioambientales 0 culturales.

Los proveedores de servicios tecnológico, jurídico y de asesoramiento en la banca son escasos, estando el mercado muy concentrado, de modo que su influencia en la banca es grande. Del mismo modo, los ahorradores tienen la fuerza que supone la capacidad de depositar sus ahorros en entidades que se ajusten a sus intereses, tanto de rentabilidad como en los proyectos que financian. 


\section{Tabla 3. Análisis de las cinco fuerzas de Porter para Triodos Bank}

\begin{tabular}{|l|c|}
\hline Fuerzas & Grado \\
\hline Poder de negociación de clientes & Alto \\
Poder de negociación de proveedores & Medio-Alto \\
Amenaza de nuevos competidores & Bajo \\
Amenazas de productos o servicios sustitutivos & Bajo \\
Rivalidad entre competidores & Bajo \\
\hline
\end{tabular}

FUENTE: Elaboración propia

\subsubsection{Principales competidores}

En España, Triodos Bank es líder entre las entidades que promueven las finanzas éticas respondiendo a los principios de economía social y solidaria. Entre sus competidores más destacados se encuentran: Fiare Banca Ética, banco ético desde 2005 que surge de la unión de la italiana Banca Popolare Etica y la vasca Fundación Fiare, que financia proyectos de la economía social y solidaria; Coop57, cooperativa de servicios financieros éticos y solidarios; y, en menor medida, Oikocredit, cooperativa que proporciona crédito para el desarrollo, financiando proyectos que reduzcan la pobreza en los países del Sur (véase la Tabla 4). Ciertamente Coop57 y Oikocredit no son entidades bancarias, por lo que sus operaciones no son coincidentes en sentido estricto con las de Triodos Bank, de modo que la consideración de competidores habría que entenderla dentro de su diferenciación.

\section{Tabla 4. Datos económicos de Triodos Bank España y sus competidores en 2016 (en miles de euros)}

\begin{tabular}{|l|ccc|}
\hline & Volumen Ahorro & Volumen Préstamos & No Préstamos \\
\hline Triodos Bank España & 1.860 .438 & 969.194 & 8.905 \\
FIARE Banca Ética & 91.685 & 36.537 & 107 \\
Coop57 & 30.641 & 8.891 & 245 \\
\hline
\end{tabular}

FUENTE: Elaboración propia a partir de los Informes Anuales (2016).

No obstante, hay que señalar que los ahorradores tienen la fuerza que supone la capacidad de depositar sus ahorros en entidades que se ajusten a sus intereses, tanto de rentabilidad como en los proyectos que financia; y es aquí donde la banca ética genera su cuota de mercado. 


\subsubsection{Amenazas y oportunidades}

En el desarrollo de la actividad bancaria, Triodos Bank se enfrenta a una serie de amenazas como la posible estrategia de entrada de la banca tradicional en el sector de banca ética para lavar su imagen perjudicada durante la crisis; la regulación de su actividad, puesto que este sector destaca por su flexibilidad; insuficientes recursos financieros que pongan en peligro la realización de los proyectos de inversión; $y$, una estructura organizativa con escasas sucursales que desmotive al cliente potencial de los productos y servicios (Tabla 6).

Sin embargo, pueden surgir oportunidades para Triodos en línea con la actual situación económica, política y social que genera una demanda por parte de la sociedad de otro tipo de productos y servicios financieros, conscientes de la influencia de las entidades financieras en el desarrollo de los países. Así, Triodos como exponente de la banca ética en España, con su compromiso social y medioambiental debe hacer frente a nuevas oportunidades de mercado, accediendo a clientes desencantados con la banca tradicional. Por otro lado, estos clientes requieren nuevos productos y servicios financieros que aporten rentabilidad social, cultural o medioambiental, además de económica.

El avance de este sector va a requerir cooperación y asociación entre los bancos, cooperativas y organizaciones que lo conforman, para así llevar a cabo proyectos de mayor envergadura y acceder a un mayor número de clientes.

Asimismo, la entidad, en base al principio de transparencia y para establecer una clara diferencia con la banca tradicional, comunica cada uno de los proyectos en los que invierte, explicando con detalle su modelo de gestión y presentando la información financiera y no financiera disponible para todos los grupos de interés.

Cabe señalar también que las bajas rentabilidades del mercado financiero actual hacen que muchos clientes depositen sus ahorros en entidades conscientes del valor ético, social, cultural y medioambiental de los proyectos que financian; así, estos clientes están dispuestos a sacrificar parte de su rentabilidad conociendo que su dinero está financiando proyectos éticos y sostenibles, acordes con sus valores.

De la misma forma, grandes corporaciones y entidades públicas utilizan la banca con valores para renovar su imagen e incrementar su reputación de cara a sus clientes, puesto que la crisis ha dejado al descubierto las malas prácticas que pusieron en práctica. También es evidente que la transformación digital supone una oportunidad para la banca ética frente a la tradicional, y buscan dar un servicio de calidad por medio de Internet y otras vías telemáticas al no disponer de una red de sucursales extensa.

Por todo esto, en 2016 ha desarrollado productos y servicios financieros enfocados en un cliente que busca una forma de hacer banca no especulativa. Por ejemplo, ha lanzado un plan de pensiones con criterios de inversión socialmente responsable y de impacto. Además, en la continua búsqueda de crear nuevas vías de usar el dinero de forma responsable, ponen en marcha una aplicación para 
teléfonos móviles de consumo responsable y crean una plataforma de crowdfunding o microfinanciación colectiva para huertos educativos.

En definitiva, en España Triodos Bank ocupa una posición de liderazgo en el sector de la banca ética, tanto por volumen de recursos como por volumen de créditos concedidos. La crisis ha derivado en un malestar común en la sociedad con la actividad realizada por la banca tradicional que está favoreciendo la implantación de entidades alternativas y, como consecuencia, se están financiando proyectos que estaban excluidos de la financiación por su baja rentabilidad económica.

\subsection{Análisis interno}

Continuando con el análisis de la situación estratégica de Triodos Bank en España, es necesario observar en un análisis interno de la actividad del banco las estrategias más adecuadas que posicionen a la entidad en un lugar más destacado en el sector financiero español, así como lograr mayores utilidades para sus clientes.

Para realizar este análisis se han utilizado cuatro modelos empleados en el ámbito empresarial: en primer lugar, se definen las debilidades y fortalezas encontradas en Triodos; en segundo, se analizan los recursos que aportan una ventaja competitiva según el modelo VRIO; en tercero, se estudia la Cadena de Valor descrita por Porter (1985) para la entidad, que describe el desarrollo de las actividades desarrolladas por el banco para generar valor al cliente; y, por último, se analizan, tanto la estructura organizativa como los datos sociales y medioambientales, de Triodos Bank.

\subsubsection{Debilidades y fortalezas}

En consecuencia, se detectan las actividades que realiza con menos eficiencia y cuáles son las que desarrolla de una forma efectiva, aportándole una ventaja competitiva. Así, Triodos Bank España, por su concepto de crecimiento progresivo y firme, no dispone de sucursales en todas las provincias de España ni tiene acuerdos con otras entidades bancarias para la utilización de sus redes de cajeros, lo que le puede suponer un inconveniente para captar la atención de un cliente acostumbrado a la banca tradicional y el trato directo con el empleado de la banca.

La toma de decisiones de la entidad está centralizada en los Países Bajos, y las directrices que toma la corporación pueden estar basadas en una situación política, social, económica y financiera que dista de la española. 


\section{Tabla 5. Cifras actividades bancarias por país y unidad de negocio (2016)}

\begin{tabular}{|c|c|c|c|c|c|c|}
\hline & Países Bajos & Bélgica & Reino Unido & España & Alemania & Total TriodosB. \\
\hline Localización geográfica & Zeist & Bruselas & Brístol & Madrid & Fráncfort & \\
\hline $\mathrm{N}^{0}$ de clientes (en miles) & 299 & 71 & 45 & 224 & 13 & 652 \\
\hline Depósitos clientes (millones de euros) & 3.213 & 1.657 & 1.077 & 1.860 & 224 & 8.031 \\
\hline$N^{0}$ de cuentas & 384.651 & 73.696 & 52.209 & 234.737 & 14.445 & 759.738 \\
\hline Inversión crediticia (millones de euros) & 2.334 & 1.324 & 831 & 969 & 250 & 5.708 \\
\hline $\mathrm{N}^{0}$ de créditos & 34.154 & 3.286 & 1.290 & 8.905 & 3.130 & 50.765 \\
\hline Balance total (millones de euros) & 3.741 & 1.895 & 1.269 & 2.048 & 308 & 9.262 \\
\hline Beneficio neto (miles de euros) & 12.954 & 9.074 & 5.130 & 76 & -1.383 & 25.851 \\
\hline Costes de explotación/total de ingresos & $71 \%$ & $68 \%$ & $78 \%$ & $94 \%$ & $122 \%$ & $78 \%$ \\
\hline $\mathrm{N}^{0}$ de empleados a jornada completa & 181,3 & 119,8 & 144,8 & 275,2 & 45,0 & 766 \\
\hline Empleados por contrato (Indefinido/Temporal) & $34 / 190\left(^{*}\right)$ & $2 / 125$ & $13 / 140$ & $12 / 281$ & $1 / 56$ & n.d. \\
\hline
\end{tabular}

(*) Incluye Países Bajos y Banca Privada (Países Bajos)

FUENTE: Triodos Bank. Informe Anual 2016.

En otro sentido, Triodos Bank España forma parte de un grupo bancario consolidado en cinco países europeos con un volumen de negocio que crece de manera considerable todos los años. En 2016 y dentro de Grupo Triodos, España sigue a los Países Bajos en número de clientes, depósitos, cuentas, y patrimonio total gestionado; y en la ratio entre los costes de explotación y el total de ingresos, $94 \%$, a Alemania, $122 \%$; destaca en el grupo en el número de empleados con equivalencia a jornada completa con 276, mientras que es el país con más contratos a tiempo definido, siendo 281 a cierre del ejercicio 2016 (véase Tabla 5). Todas las cifras que aporta anualmente están en la línea de una entidad cuyo valor esencial es la transparencia en todas las actividades que realiza, de modo que el cliente conoce con exactitud en qué proyectos está invertido su dinero, así como la rentabilidad económica, social y medioambiental que está generando. Asimismo, en relación con sus competidores directos, es la entidad de banca ética que dispone de más sucursales físicas en España.

Desde el punto de vista financiero, dispone de suficientes recursos para llevar a cabo su actividad de manera rentable y sostenible, y cuenta con las dotaciones establecidas por el Banco de España que le permiten operar. Igualmente, ofrece productos y servicios financieros similares a los de la banca tradicional, como cuentas corrientes, depósitos, tarjetas de crédito, hipotecas, etc., que le permite cubrir las necesidades financieras de los clientes.

Así, la Tabla 6 muestra un resumen del análisis DAFO que acabamos de realizar. 


\section{Tabla 6. Análisis DAFO}

\begin{tabular}{|l|l|}
\hline Debilidades & $\begin{array}{l}\text { 1. Escasa infraestructura (sucursales y red de cajeros) } \\
\text { 2. No tiene arraigo en España } \\
\text { 3. Toma de decisiones en Holanda } \\
\text { 4. Al ser un banco europeo consolidado, los clientes pueden confundirlo con un banco tradicional }\end{array}$ \\
\hline Amenazas & $\begin{array}{l}\text { 1. Entrada de la banca tradicional en el sector ético } \\
\text { 2. Cambio en la legislación que perjudique su actual flexibilidad } \\
\text { 3. Aumento de las tasas de morosidad } \\
\text { 4. Insuficientes recursos } \\
\text { 5. Insuficiente estructura organizativa }\end{array}$ \\
& $\begin{array}{l}\text { 1. Es un banco consolidado a nivel europeo } \\
\text { 2. Es el banco ético líder en España } \\
\text { 3. Transparencia en sus actividades } \\
\text { 4. Tiene mayor infraestructura que sus competidores éticos } \\
\text { 5. El control de las decisiones está en la Fundación para la Administración de Acciones de Triodos (SAAT) } \\
\text { y no en manos de los accionistas } \\
\text { 6. Entidad financieramente saneada } \\
\text { 7. Clara definición de sus valores éticos } \\
\text { 8. Personal capacitado } \\
\text { 9. Provee todo tipo de productos y servicios financieros, lo que le permite ser competitivo con la banca tradicional }\end{array}$ \\
\hline Oportunidades & $\begin{array}{l}\text { 1. Demanda de productos y servicios financieros éticos por parte de la sociedad } \\
\text { 2. Creación de nuevos productos y servicios financieros } \\
\text { 3. Cooperación entre entidades de banca ética } \\
\text { 4. Pérdida de interés en los productos de la banca tradicional por la baja rentabilidad de los mismos } \\
\text { 5. Desarrollo de nuevas tecnologías que posibilita, con baja infraestructura, el acceso a los clientes }\end{array}$ \\
\hline
\end{tabular}

FUENTE: Elaboración propia.

\subsubsection{Modelo VRIO}

La posición competitiva de la entidad financiera está en la heterogeneidad de los recursos estratégicos que controla, de modo que su ventaja competitiva estará en la implantación de una estrategia de creación de valor ante sus competidores. Así, el modelo VRIO de Barney y Griffin (1992) señala que un recurso es VRIO si aporta una ventaja competitiva, es decir, si reúne los atributos: valioso (V), raro o escaso $(R)$, inimitable $(I)$ y relacionado con la Organización de la empresa $(0)$.

Una vez se aplica el modelo a Triodos Bank, identificando los recursos internos (tangibles e intangibles) que le proporcionan una ventaja competitiva sostenible, se observa que a largo plazo dispone de unos recursos competitivos que le permitirán mantenerse como líder en el sector (véase Tabla 7). 


\section{Tabla 7. Análisis VRIO de Triodos Bank}

\begin{tabular}{|l|lllll|c|}
\hline Recursos & V & R & I & 0 & Implicación competitiva \\
\hline $\begin{array}{l}\text { Recursos Tangibles: } \\
\text { Red de sucursales bien distribuidas } \\
\text { por el territorio español }\end{array}$ & Sí & No & No & Sí & $\begin{array}{c}\text { Paridad Competitiva } \\
\text { (atributos que presentan la } \\
\text { mayoría de empresas del sector) }\end{array}$ \\
\hline $\begin{array}{l}\text { Recursos Humanos: } \\
\text { Personal formado y con experiencia } \\
\text { en el sector bancario }\end{array}$ & Sí & Sí & Sí & Sí & $\begin{array}{c}\text { Ventaja Competitiva } \\
\text { Sostenible }\end{array}$ \\
\hline $\begin{array}{l}\text { Recursos Intangibles: } \\
\text { Imagen sólida, de un grupo financiero } \\
\text { con una trayectoria profesional exitosa }\end{array}$ & Sí & Sí & Sí & Sí & $\begin{array}{l}\text { Ventaja Competitiva } \\
\text { Sostenible }\end{array}$ \\
\hline $\begin{array}{l}\text { Cartera de clientes que comparten los } \\
\text { valores de la entidad }\end{array}$ & Sí & No & Sí & No & Paridad Competitiva \\
\hline
\end{tabular}

FUENTE: Elaboración propia

Estos recursos se refieren tanto al personal cualificado, que comparte la cultura de la entidad y es responsable con sus decisiones, como a los relacionados con su reputación como banco ético de referencia en Europa y, de este modo, Triodos es visto por sus clientes e inversores como una entidad comprometida con los valores sociales y medioambientales.

\subsubsection{Cadena de valor}

A partir del análisis a Triodos Bank de la herramienta de gestión de la Cadena de Valor de Porter, se identificarán las actividades generadoras de valor que supondrán obtener una ventaja competitiva. Se optimizará el proceso productivo, reduciendo costes, y la eficiencia en la utilización de servicios iniciales, para así aumentar el margen, entendido como la diferencia entre el valor total y los costes totales incurridos por la empresa para desempeñar las actividades generadoras de valor (véase Tabla 8).

Para el desarrollo de la ventaja competitiva es fundamental definir el servicio que Triodos Bank ofrece y dónde se suministra, para influir en el margen y en la fidelidad del cliente. Por otro lado, es necesario reclutar a los mejores profesionales, además de tener una buena capacidad negociadora. En general, es fundamental subrayar la importancia en la coordinación entre las actividades para obtener la ventaja. 


\section{Tabla 8. Cadena de Valor de Triodos Bank}

\begin{tabular}{|c|l|c|c|c|}
\hline \multirow{2}{*}{} & \multicolumn{4}{|l|}{ Aprovisionamientos } \\
Actividades para el buen funcionamiento de la actividad: compras de material de oficina, limpieza, \\
seguridad, etc.
\end{tabular}

FUENTE: Elaboración propia.

Una ventaja competitiva es perdurable si no es fácilmente transferible por sus competidores, de modo que Triodos destacará si desarrolla un valor en los clientes que preferirán adquirir sus productos y servicios frente a otras entidades del sector.

\subsubsection{Estructura organizativa}

Triodos Bank es una institución financiera independiente, destacando así las discrepancias organizativas con el resto de entidades financieras implantadas en Europa y en España, puesto que trata de evitar estar sometida a los intereses especulativos de los mercados financieros y proteger su misión sostenible a largo plazo (véase Gráfico 2). 


\section{Gráfico 2. Estructura Grupo Triodos Bank 2016}

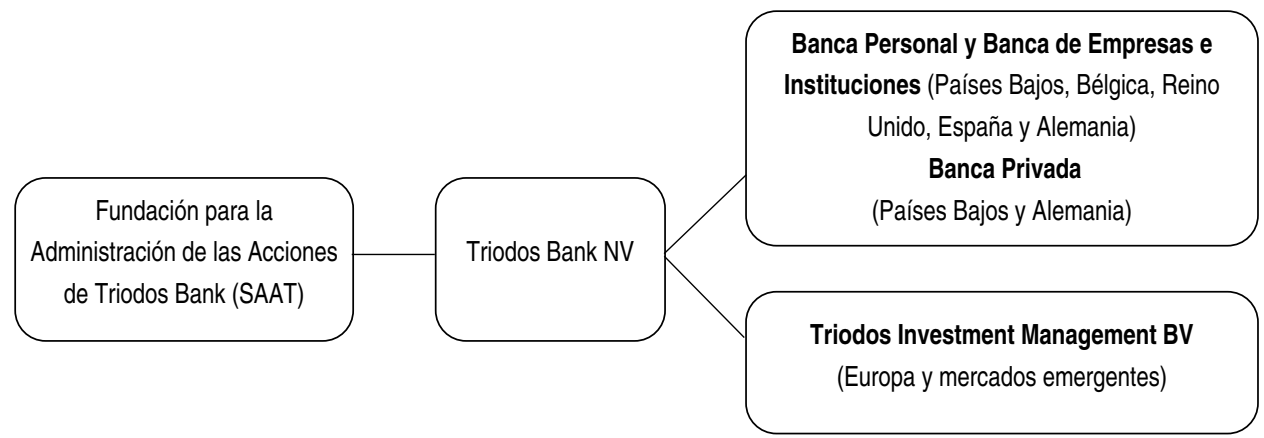

FUENTE: Elaboración propia a partir de Informe Anual (2016)

La Fundación para la Administración de las Acciones de Triodos (SAAT), le permite tener el control en la toma de decisiones y no estar sometido al poder de los accionistas. Es el organismo que salvaguarda la misión de Triodos Bank, su independencia y los intereses económicos de sus titulares de certificados de depósito, que a su vez nombra a la Junta. Gestiona todas las acciones que constituyen el capital social, dividido en Certificados de Depósito para Acciones (CDA), sin derecho a voto, y se encarga, por otro lado, de emitirlos y tramitar su compra. Los titulares de los certificados disfrutarán de los derechos económicos ligados a estas acciones, como son el derecho a percibir dividendos, pero no dan el derecho de control sobre la entidad. Ningún titular de certificados puede emitir un número mayor de 1.000 votos, con independencia del número de certificados de acciones que posea, con lo que así evitan el exceso de poder de los inversores que poseen un porcentaje alto de capital.

De este modo, las sucursales de Triodos Bank en España actúan como comercializadores de los certificados emitidos desde Holanda por la Fundación, donde se gestiona tanto el pago de dividendos como la remuneración alternativa consistente en la suscripción gratuita de nuevos depósitos.

\section{Tabla 9. No de titulares de Certificados de Depósito del Grupo Triodos Bank (2012-2016)}

\begin{tabular}{|c|ccccc|}
\hline & 2012 & 2013 & 2014 & 2015 & 2016 \\
\hline $\mathrm{N}^{\circ}$ titulares CDA & 26.876 & 31.304 & 32.591 & 35.735 & 38.138 \\
\hline
\end{tabular}

FUENTE: Triodos Bank. Informe Anual 2016. 
La evolución en el número de titulares de CDA se ha incrementado en los últimos años en cada uno de los países del grupo, aumentando su capital social (Tabla 9). Cumple así con los requerimientos exigidos por los organismos europeos y ofrece muestras de solvencia y solidez en el desarrollo de la actividad bancaria.

\section{Gráfico 3. Titulares de Certificados de Depósito de Acciones por país y año (2014-2016)}

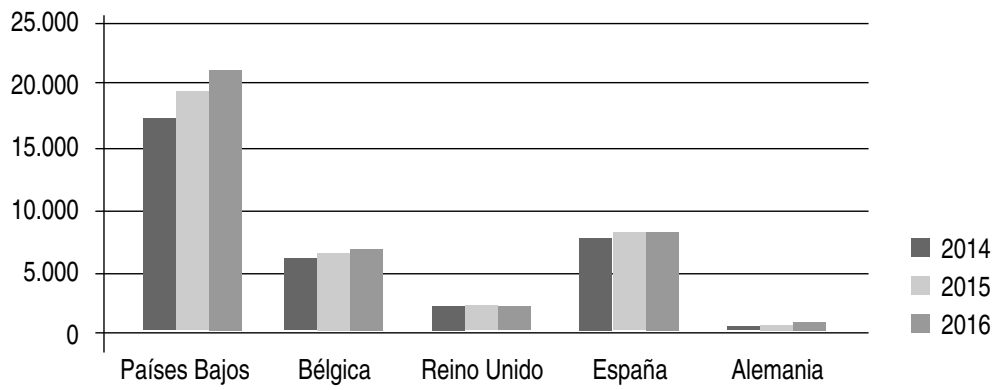

FUENTE: Triodos Bank. Informe Anual 2016.

La mayoría de las titularidades de los certificados se encuentran en los Países Bajos, donde tiene su origen Triodos y su implantación es mayor. España ocupa la segunda posición debido a la gestión comercial de las sucursales que transmiten la misión y los valores de la entidad, consolidando así su implantación (véase Gráfico 3).

\subsubsection{Datos sociales y medioambientales}

El principio de transparencia en el que se apoya Triodos Bank no sólo abarca la información referente a la actividad desarrollada con sus clientes, sino también con otros grupos de interés, como son los empleados, conocedor de la ventaja competitiva sostenible que aportan al banco. De este modo, anualmente publica un informe donde recoge información acerca del número de empleados, el absentismo laboral, retribuciones y gasto en formación o antigüedad, con el propósito de ser transparente con sus depositantes e inversores acerca del coste que le supone a la entidad realizar su actividad de manera eficiente (véase Tabla 10). 


\section{Tabla 10. Evolución datos sociales (2012-2016)}

\begin{tabular}{|l|ccccc|}
\hline & $\mathbf{2 0 1 2}$ & $\mathbf{2 0 1 3}$ & $\mathbf{2 0 1 4}$ & $\mathbf{2 0 1 5}$ & $\mathbf{2 0 1 6}$ \\
\hline $\mathrm{N}^{\circ}$ de empleados & 788 & 911 & 1.017 & 1.121 & 1.271 \\
\hline $\mathrm{N}^{\circ}$ medio de empleados a jornada completa durante año & 694 & 785 & 883 & 974 & 1.089 \\
\hline $\begin{array}{l}\mathrm{N}^{\circ} \text { medio de empleados a jornada completa } \\
\text { a cierre del ejercicio }\end{array}$ & 722 & 838 & 931 & 1.021 & 1.155 \\
\hline Media edad de empleados (años) & 39,5 & 39,6 & 39,7 & 40,4 & 40,7 \\
\hline Media antigüedad laboral (años) & 4,6 & 4,7 & 4,8 & 4,8 & 4,9 \\
\hline Bajas por enfermedad & $2,8 \%$ & $2,7 \%$ & $2,6 \%$ & $2,6 \%$ & $3 \%$ \\
\hline Índice de rotación (primer año) & $9,6 \%$ & $7,2 \%$ & $9,5 \%$ & $14 \%$ & $7,9 \%$ \\
\hline Días de formación por empleado & 4,5 & 3,7 & 4,3 & 4,6 & 3,7 \\
\hline Media gasto de formación por empleado $(€)$ & 1.731 & 2.055 & 1.856 & 1.692 & 1.435 \\
\hline Porcentaje de mujeres con cargos directivos & $42 \%$ & $40 \%$ & $40 \%$ & $38 \%$ & $40 \%$ \\
\hline $\begin{array}{l}\text { Diferencia entre el salario más alto y } \\
\text { la mediana de salarios a jornada completa }\end{array}$ & 5,5 & 5,5 & 5,6 & 5,7 & 5,7 \\
\hline $\begin{array}{l}\text { Diferencia entre el salario más alto y } \\
\text { el más bajo a jornada completa }\end{array}$ & 9,4 & 9,4 & 9,6 & 9,8 & 9,9 \\
\hline
\end{tabular}

FUENTE: Triodos Bank. Informe Anual 2016.

El número de empleados en el Grupo Triodos ha ido aumentando cada año; en el caso de la sucursal española, cerró el ejercicio 2016 con una media de 293 empleados a jornada completa, lo que supone un incremento del $9,3 \%$ más que en 2015 , consolidándose la implantación de la entidad ética. El absentismo del 2,8\% es bajo si se compara con el 15\% en España, según la Asociación de Mutuas de Accidentes de Trabajo (AMAT), mientras que el índice de rotación ha crecido, debido a las reformas laborales que se han producido en algunos países socios europeos.

Destaca el dato aportado sobre el porcentaje de mujeres ocupando puestos directivos, que en 2016 es del 40\%, cifra que confirma el compromiso de Triodos Bank con la paridad de género; el número de mujeres en la plantilla fue de 654 , un $51,5 \%$ del total, reflejando un equilibrio de género en relación con el mercado, en línea con el fomento de la igualdad entre hombre y mujer, así como con la conciliación laboral.

El éxito de la implantación de Triodos depende en gran medida de las personas que trabajan en la entidad, que estén cualificadas y motivadas con la misión, y sean capaces de ponerla en práctica diariamente en el desarrollo de su trabajo. Así, la entidad apuesta por invertir una parte importante de sus recursos en programas de formación y desarrollo profesional, con el propósito de formar a sus empleados en los temas que estimen más necesarios. En este sentido, el gasto medio en formación por empleado en 2016 fue de 1.731 euros, lo que significa que Triodos es consciente de la valía 
de su capital humano y entiende que la formación del personal aumentará su productividad, de modo que ofrecerá un mejor servicio a los clientes, reducirá el absentismo laboral, aumentará la competitividad y la flexibilidad ante los posibles cambios en el entorno.

Otro aspecto destacable de Triodos son las retribuciones al personal; para ello ha establecido una política salarial que abarca a todos los empleados de la entidad. Precisamente, no ofrece bonus o regímenes de opciones sobre acciones a los miembros de la dirección ni a los empleados, no lo considera propio de una banca ética, sino que en base a acuerdos de recuperación puede conceder asignaciones adicionales a los empleados hasta un máximo del salario correspondiente a un mes y con un máximo anual de 10.000 euros brutos. Además, podrá decidirse el pago de una gratificación anual colectiva por los logros y la contribución global de toda la plantilla, con un máximo de 500 euros, pudiendo abonarse en efectivo o mediante CDA. Asimismo, se realizará un seguimiento exhaustivo del factor que regula la desviación entre el salario máximo pagado en la categoría más baja y el salario máximo pagado a los altos directivos, para garantizar que esta diferencia no sea excesiva $(9,4$ veces en 2016); las indemnizaciones por despido serán modestas y, en ningún caso, deberán constituir una gratificación por resultados negativos.

Por otro lado, Triodos entre los datos no financieros que aporta anualmente, incluye los resultados medioambientales obtenidos, en los que detalla el consumo de recursos realizados durante el período (consumos de gas, electricidad, papel, desplazamientos, etc.), y las emisiones de CO2 que causan el funcionamiento de su actividad, para lo cual tiene establecido un plan de compensación de dichas emisiones, además de respetar la normativa medioambiental establecida por la institución independiente de sostenibilidad Global Reporting Initiative (GRI) sobre la elaboración de memorias de sostenibilidad (véase Tabla 11).

\section{Tabla 11. Evolución datos medioambientales (2012-2016)}

\begin{tabular}{|l|ccccc|}
\hline $\begin{array}{l}\text { Emisiones de } \mathrm{CO}_{\mathbf{2}} \text { (equivalentes) } \\
\text { en miles de kg }\end{array}$ & $\mathbf{2 0 1 2}$ & $\mathbf{2 0 1 3}$ & $\mathbf{2 0 1 4}$ & $\mathbf{2 0 1 5}$ & $\mathbf{2 0 1 6}$ \\
\hline Electricidad & 353 & 96 & 100 & 1 & 22 \\
Consumo de gas (calefacción) & 112 & 130 & 124 & 90 & 73 \\
Papel & 468 & 265 & 314 & 293 & 203 \\
Transporte público & 209 & 224 & 260 & 214 & 243 \\
Automóviles & 865 & 1.046 & 1.145 & 1.324 & 1.499 \\
Vuelos & 936 & 1.145 & 1.141 & 1.119 & 1.083 \\
\hline Total & 2.953 & 2.906 & 3.084 & 3.041 & 3.123 \\
Menos: Compensación por créditos de $\mathrm{CO}_{2}$ & -2.953 & -2.906 & -3.084 & -3.041 & -3.123 \\
Saldo de $\mathrm{CO}_{2}$ (neutral) & - & - & - & - & - \\
Costes de compensación de $\mathrm{CO}_{2}$ por tonelada $(€)$ & 12,50 & 12,50 & 8,40 & 8,40 & 8,40 \\
\hline
\end{tabular}

FUENTE: Triodos Bank. Informe Anual 2016 


\section{Conclusiones}

La inclusión del modelo bancario de la Banca Ética en España es relativamente reciente; de hecho, en el sistema financiero español aún no se ha fundado ninguna entidad. Hasta ahora la corriente ha sido establecer sucursales, continuando con el modelo aplicado por otras entidades consolidadas en otros países, como son los casos de Triodos Bank y Fiare Banca Ética, y actuar de acuerdo con líneas de financiación dirigidas al desarrollo de proyectos sostenibles, compartiendo activamente este segmento de negocio bancario con entidades financieras de la banca tradicional, como BBVA, CaixaBank y Banco Santander. Este sector puede llegar a saturarse y, de alguna forma, diluir los esfuerzos por conseguir que la percepción de la sociedad esté basada en un modelo de negocio que incluya resultados sociales, medioambientales, culturales y económicos. También ejercen un papel importante en la consecución de establecer y consolidar un modelo de finanzas éticas, aunque más residual, los casos de cooperativas que comercializan productos de ahorro y financiación éticos, como son Oikocredit y Coop57.

Las características de los clientes de la banca ética están correlacionadas con las del modelo de empresa o del proyecto en el que desean invertir sus ahorros, ejerciendo así un papel esencial en la inclusión financiera y el apoyo a territorios y poblaciones para los que la banca tradicional había actuado como un muro al negarle el crédito necesario para su desarrollo.

Para que la banca ética no sea una simple ilusión asociada a períodos de crisis financieras y se convierta definitivamente en una alternativa consistente, deberá ofertar servicios y productos con cierta similitud a la banca convencional y unas rentabilidades económica y social que aporten credibilidad y una clara diferenciación en igualdad de condiciones con la banca tradicional.

En la actualidad, Triodos Bank es la entidad que con más interés promueve un uso consciente del dinero con la finalidad de crear una sociedad más próspera, alejada de la especulación. El principal valor que aporta la entidad es el de financiar proyectos que cumplan con una serie de requisitos éticos, sin la necesidad de los avales exigidos por las entidades financieras tradicionales. Lleva a cabo iniciativas y proyectos de desarrollos locales que no tendrían cabida en un sistema financiero en el que sólo prima la rentabilidad económica.

Así, como banco ético pone a disposición de la misión que lidera a empleados cualificados con experiencia en los sectores sociales, culturales y medioambientales, de manera que los recursos financieros captados de clientes leales que comparten valores con la entidad, financiarán únicamente a empresas sostenibles de la economía real, siempre informando con la máxima transparencia a sus grupos de interés. 
Por todo esto, la banca ética se aproxima a una realidad puesto que demuestra que las finanzas son compatibles con la ética y el beneficio social. La última crisis financiera debe hacer recapacitar a los usuarios y clientes de la banca tradicional, y reclamar a sus ahorros unos criterios éticos en las políticas de inversiones de estas entidades financieras.

Para finalizar, debemos señalar que la regulación estricta de las finanzas éticas debe suponer la oportunidad y finalidad que la banca ética necesita, de modo que Triodos Bank se implante en el sistema financiero definitivamente como una entidad cooperativa, supervisora de la actividad bancaria con función social y confirme que es una alternativa viable a un modelo más especulativo.

\section{Referencias bibliográficas}

ALEJOS GÓNGORA, C.L. (2014): "Banca ética: una alternativa viable", IESE Business School. Universidad de Navarra. Cuadernos de la Cátedra "Ia Caixa" de Responsabilidad Social de la Empresa y Gobierno Corporativo, 23.

Disponible en: www.iese.edu/es/multimedia/CatedralaCaixa_Cuaderno_23_tcm42-166151.pdf

ALEMÁN ALONSO, J.J. (2015): "El crecimiento de la banca ética en España frente al descrédito de la banca tradicional", Actas I Congreso internacional de la Red española de Filosofía, Vol. XV, pp. 67-78.

Disponible en: redfilosofia.es/wp-content/uploads/sites/4/2015/06/9.alexalemanes@yahoo.es_.pdf

ALFONSO, R. (2016): "Economía colaborativa: un nuevo mercado para la economía social", CIRIECEspaña, Revista de Economía Pública, Social y Cooperativa, 88, 231-258.

BANCO DE ESPAÑA (2017): Informe sobre la crisis financiera y bancaria en España, 2008-2014. Disponible en: http://www.bde.es/bde/es/secciones/informes/Otras_publicacio/informe-sobre-la/

BARAIBAR-DIEZ, E., ODRIOZOLA, M.D. \& FERNÁNDEZ SÁNCHEZ, J.L. (2017): "Communication transparency in ethical and traditional banking in Spain", Journal of International Business Research and Marketing, 2(2), 24-32. DOI: http://dx.doi.org/10.18775/jibrm.1849-8558.2015.22.3004

BOSHEIM, S.A. (2012): "Social banks and impact measurement: The cases of Charity Bank and Triodos Bank", ISB Paper Series, 10.

Disponible en: http://www.social-banking.org/research/isb-paper-series/no-10-dec-12/

BUENDÍA, I., REDJAH, Y. \& TREMBLAY, B. (2012): "Las cooperativas de servicios financieros en el continente americano", Ekonomiaz, 79, 200-233. 
CABALEIRO CASAL, M.J. \& RODRÍGUEZ PARADA, S.M. (2008): "Sociedades cooperativas de banca alternativa", REVESCO, Revista de Estudios Cooperativos, 95, 44-64.

CALDARELLI, A., FIONDELLA, C., MAFFEI, M. \& ZAGARIA, C. (2016): "Managing risk in credit cooperative banks: Lessons from a case study", Management Accounting Research, 32, 1-15.

DOI: http://dx.doi.org/10.1016/j.mar.2015.10.002

CASTRO COTÓN, M. \& ROMERO CASTRO, N. (2011): "Cooperativas de crédito y banca ética: ¿Un camino por explorar?", CIRIEC-España, Revista de Economía Pública, Social y Cooperativa, 72, 263-300.

CHEW, B.C., TAN, L.H. \& HAMID, S.R. (2016): "Ethical banking in practice: a closer look at the Cooperative Bank UK PLC", Qualitative Research in Financial Markets, 8(1), 70-91.

CONDOSTA, L. (2012): "How banks are supporting local economies facing the current financial crisis: An Italian perspective", International Journal of Bank Marketing, 30(6), 485-502.

CORNÉE, S. (2017): "The relevance of soft information for predicting small business credit default: Evidence from a social bank", Journal of Small Business Management, L(2).

CORNÉE, S., KALMI, P. \& SZAFARZ, A. (2016): "Selectivity and transparency in social banking: Evidence from Europe", Journal of Economic Issues, 50(2), 494-502.

COWTON, C.J. \& THOMPSON, P. (2001): "Financing the social economy: a case study of Triodos Bank", International Journal of Nonprofit and Voluntary Sector Marketing, 6(2), 145-155.

DE LA CRUZ AYUSO, C. \& SASIA SANTOS, P.M. (2010): "La banca ética como herramienta de acción política". Icade: Revista de las Facultades de Derecho y Ciencias Económicas y Empresariales, $80,185-210$.

DE LA CRUZ AYUSO, C., SASIA SANTOS, P.M. \& GARIBI, J. (2006): "Lo que debe ser y es una a banca ética", Lan harremanak: Revista de relaciones laborales, 14, 175-204.

DE LA ORDEN DE LA CRUZ, C. \& SÁNCHEZ GONZÁLEZ, P. (2016): "Desarrollos de banca ética y viabilidad de la banca islámica", Opción, 32(9).

DORASAMY, N. (2013): "Corporate Social Responsibility and Ethical Banking for Developing Economies", Journal of Economics and Behavioral Studies, 5(11), 777-785.

FERNÁNDEZ OLIT, B. \& DE LA CUESTA GONZÁLEZ, M. (2014): "Evaluación de impactos ambientales y sociales del negocio de banca comercial en Europa durante el periodo 2006-2010". Estudios de economía aplicada, 32(2), 567.

GASSIOT BALLBÈ, R. (2013): "Las finanzas éticas como instrumento al servicio de la economía solidaria. La experiencia de Coop57", Cuadernos de Trabajo Social, 26-1, 75-84.

DOI: http://dx.doi.org/10.5209/rev_CUTS.2013.v26.n1.40596 
GLOBAL ALLIANCE FOR BANKING ON VALUES (GABV) (2017): Members.

Disponible en: http://www.gabv.org/the-community/members

GLOBAL ALLIANCE FOR BANKING ON VALUES (GABV) (2016): Economía Real-Ganancias Reales: Un caso de negocio continuo para la banca centrada en la sostenibilidad. Informe de Investigación de 2016.

Disponible en: http://www.gabv.org/news/real-economy-real-returns-continuing-business-casesustainability-focused-banking

GUTIÉRREZ NIETO, B. (2004): "Hacia una clasificación de los productos de financiación social en España: consolidación del microcrédito y primeros pasos de la creación de un banco ético". Boletín de estudios económicos, 59 (182), 23-342.

Disponible en: www.redalyc.org/pdf/174/17421345010.pdf

HALAMKA, R. \& TEPLÝ, P. (2017): "The Effect of Ethics on Banks' Financial Performance", Prague Economic Papers, (3), 330-344.

ITURRIOZ, J., MATEU, J.L. \& VALOR, C. (2005): "La implicación de las sociedades cooperativas de crédito y las cajas de ahorros en los productos y servicios financieros socialmente responsables". Revista Vasca de Economía Social, 1, 63-84.

KARL, M. (2015): "Are Ethical and Social Banks Less Risky? Evidence from a New Dataset", Discussion Papers of DIW Berlin, DIW Berlin, German Institute for Economic Research, № 1484.

KNIGHTS, D. (2009): "The failure of regulation in banking: ethical reflections". In: 13th European Business Ethics Network UK Conference, Bristol, 6-8.

KOUSIS, M. (2017): "Alternative Forms of Resilience Confronting Hard Economic Times. A South European Perspective", Partecipazione e conflitto, 10(1), 119-135.

DOI: http://dx.doi.org/10.1285/i20356609v10i1p119

MANINI, R. \& AMAT, O. (2017): "Triodos Bank: banca con valores para mejorar el mundo y las personas", Revista de contabilidad y dirección, (24), 113-132.

MISHRA, D.K. (2015): "Green Banking: Comparing Environmental Sustainability with Socially Responsible Investments", International Journal of Biological Sciences and Engineering, Vol. 06, $\mathrm{N}^{\circ} 01, \mathrm{pp} .24-30$.

Disponible en:

https://www.academia.edu/16787897/Green_Banking_Comparing_Environmental_Sustainability _with_Socially_Responsible_Investments?auto=download

MOZIB LALON, R. (2015): "Green banking: Going green", International Journal of Economics, Finance and Management Sciences, 3(1), 34-42.

DOI: http://dx.doi.org/10.11648/j.jjefm.20150301.15

NARRILLOS ROUX, H. (2010): "EI SROI (social return on investment): un método para medir el impacto social de las inversiones", Análisis financiero, 113, 34-43. 
OCHOA BERGANZA, J. (2013): "Finanzas para una economía humana sostenible: hacia la banca ética", Revista de dirección y administración de empresas = Enpresen zuzendaritza eta administraziorako aldizkaria, 20, 123-143.

PALOMO-ZURDO, R., GUTIÉRREZ-FERNÁNDEZ, M. \& FERNÁNDEZ-TORRES, Y. (2017): "La cuestión del género en los órganos de gobierno de la banca cooperativa", CIRIEC-España, Revista de Economía Pública, Social y Cooperativa, 89, 137-166.

PAULET, E., PARNAUDEAU, M. \& RELANO, F. (2015): "Banking with ethics: Strategic moves and structural changes of the banking industry in the aftermath of the subprime mortgage crisis", Journal of Business Ethics, 131(1), 199-207.

PÉREZ-RUIZ, A. \& RODRÍGUEZ DEL BOSQUE, I. (2012): "La imagen de Responsabilidad Social Corporativa en un contexto de crisis económica: el caso del sector financiero en España", Universia Business Review, Primer Trimestre, 33, 14-29.

PULEJO, L., MARISCA, C. \& RAPPAZZO, N. (2015): "Social reporting in European ethical banks: A comparative study", International Journal of Managerial Studies and Research, 3(6), 196-202.

RELANO, F. \& PAULET, E. (2016): "A demand-driven innovation insight in the banking industry", Journal of Innovation Economics \& Management, 2, 179-195.

RELANO, F. (2015): "Disambiguating the concept of social banking", ACRN Oxford Journal of Finance and Risks Perspectives, 4(3), 48-62.

ROSERO VILLABÓN, O.G., PINZÓN, J.V. \& RAMÍREZ, G.A. (2013): "Responsabilidad Social Corporativa en la Banca Europea: un estudio empírico comparativo entre organizaciones de 15 países", Sotavento MBA, 22.

RETOLAZA ÁVALOS, J.L. \& SAN EMETERIO, J. (2003): “¿Existe espacio para una banca ética?”, Lan harremanak: Revista de relaciones laborales, 9, 127-163.

RUIZ SÁNCHEZ, B., ESTEBAN TALAYA, A. \& GUTIÉRREZ BRONCANO, S. (2014): "Reputación bancaria durante la crisis económica. Comparación entre las principales entidades financieras desde la perspectiva del cliente", Universia Business Review, Tercer trimestre, 43, 16-35.

SAN JOSÉ RUIZ DE AGUIRRE, L. \& RETOLAZA ÁVALOS, J.L. (2007): "Análisis comparativo de la banca ética con la banca tradicional: identificación de indicadores", Conocimiento, innovación y emprendedores: Camino al futuro (coord. por Juan Carlos Ayala Calvo), Universidad de La Rioja.

SAN JOSÉ RUIZ DE AGUIRRE, L., RETOLAZA ÁVALOS, J.L. \& GUTIÉRREZ GOIRIA, J. (2011): "Are Ethical Banks Different? A Comparative Analysis Using the Radical Affinity Index", Journal of Business Ethics, 100 (1), 151-173.

SAN JOSÉ RUIZ DE AGUIRRE, L., RETOLAZA ÁVALOS, J.L. \& PRUÑONOSAE, J.T. (2014): "Efficiency in Spanish banking: A multistakeholder approach analysis", Journal of International Financial Markets, Institutions \& Money, 32, 240-255. 
SANCHIS PALACIO, J.R. (2016): "La revolución de las finanzas éticas y solidarias. La economía social y solidaria: experiencias y retos", Oikonomics. Revista de Economía, Empresa y Sociedad, 6, 2834.

SANCHIS PALACIO, J.R. \& PASCUAL GARCÍA, E. (2017): "Banca ética y banca cooperativa. Un análisis comparativo a través del estudio de Caixa Popular y de Fiare Banca Ética", REVESCO, Revista de Estudios Cooperativos, 124, 1.

SASIA SANTOS, P.M. (2012): "La Banca Ética en Europa: el enfoque del crédito como criterio de configuración de un espacio de alternativa", CIRIEC-España, Revista de economía pública, social y cooperativa, 75, 276-299.

SERRANO PÉREZ, M.E. (2017): "El índice SEBI como medida del nivel de compromiso con los principios que definen la banca ética", Contaduría y Administración.

DOI: http://dx.doi.org/10.1016/j.cya.2017.06.001

SOLER TORMO, F. \& MELIÁN NAVARRO, A. (2012): "Cooperativas de crédito y banca social: viejas y nuevas respuestas éticas y solidarias a problemas de siempre", REVESCO, Revista de Estudios Cooperativos, 109, 45-80.

TOKE, D. (2005): "Community wind power in Europe and in the UK", Wind Engineering, 29(3), 301308.

TOÑA GUENAGA, A., SASIA, P. \& GARIBI, J. (2006): "Posibilidades de estructuración de una banca ética en España", Documentación Social, 142, 157-174.

TRIODOS BANK (2017): Informe anual 2016.

Disponible en: http://www.triodos-informeanual.com/es/2016/

VALOR, C., PALOMO, R., ITURRIOZ, J. \& MATEU, J.L. (2007): "Socially responsable investments among savings banks and credit unions: empirical findings in the Spanish context", Annals of Public and Cooperative Economics, 78, 301-326.

VIDAL, P., DE LA PEÑA RODRíGUEZ, M., ZARAGOZA, M. \& SUREDA, M. (2006): "Diagnóstico sobre el interés del tercer sector y la economía social por una banca ética", FETS-Financiación Ética y Solidaria. Observatorio del Tercer Sector, Barcelona. 